\title{
PERADILAN SADDAM HUSSEIN: HEGEMONI AMERIKA DAN TRAGEDI GOOD WORLD GOVERNANCE
}

\author{
Oleh: Faiz Tajul Millab
}

\section{Abstract}

After the destroying of World Trade Center USA on September 11 2001, America is focusing his international political policy on war on terrorism which was further followed by preemptive action and unilateralism toward countries considered a terrorist. One of them is Irak. Certainly the policy will hamper the realization of good world governance under the United Nations Program. Attacking Irak in 2003 is a real proof of the USA begemony in the world as the Super Power, especially concerning about Saddam Husein's process of judicature which is hold by Iraqi Special Tribunal and the Iraqi Special Tribunal is under the US intervention. Teoritically the session process of Saddam who was accused executing genocide toward Kurdi tribe should be bold by International Criminal Court (ICC) under the United Nations. It is not the competency of Iraqi Special Tribunal. The session Process of Saddam judicature is considered invalid and breaking out the principals of international law. This case will hamper the maintenance of international law supremacy. The maintenance of international law is one of the requirements of good world governance. However, the reality is showing that international politic under USA hegemony, and this will always hamper the realization of good world governance.

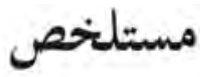

$$
\begin{aligned}
& \text { بعيد اهيار مبنى التجارة العالمية في الولايات المتحدة الأمريكية بتاريخ } 11 \text { سبتمبر } \\
& 2001 \text { تولت بؤرة السياسة الأمريكية نحو الحربب على الإرهاب، و التي ما لبثت إلا } \\
& \text { أن أتبعت بما دعي "الاستراتيجية الوقائية والانفرادية" بالضربات الوقائية بتاه الدول }
\end{aligned}
$$

Penulis adalah alumni Cross Religious and Culture Studies (CRCS) - Universitas Gadjah Mada.Email: faiztajulmillah@yahoo.com 


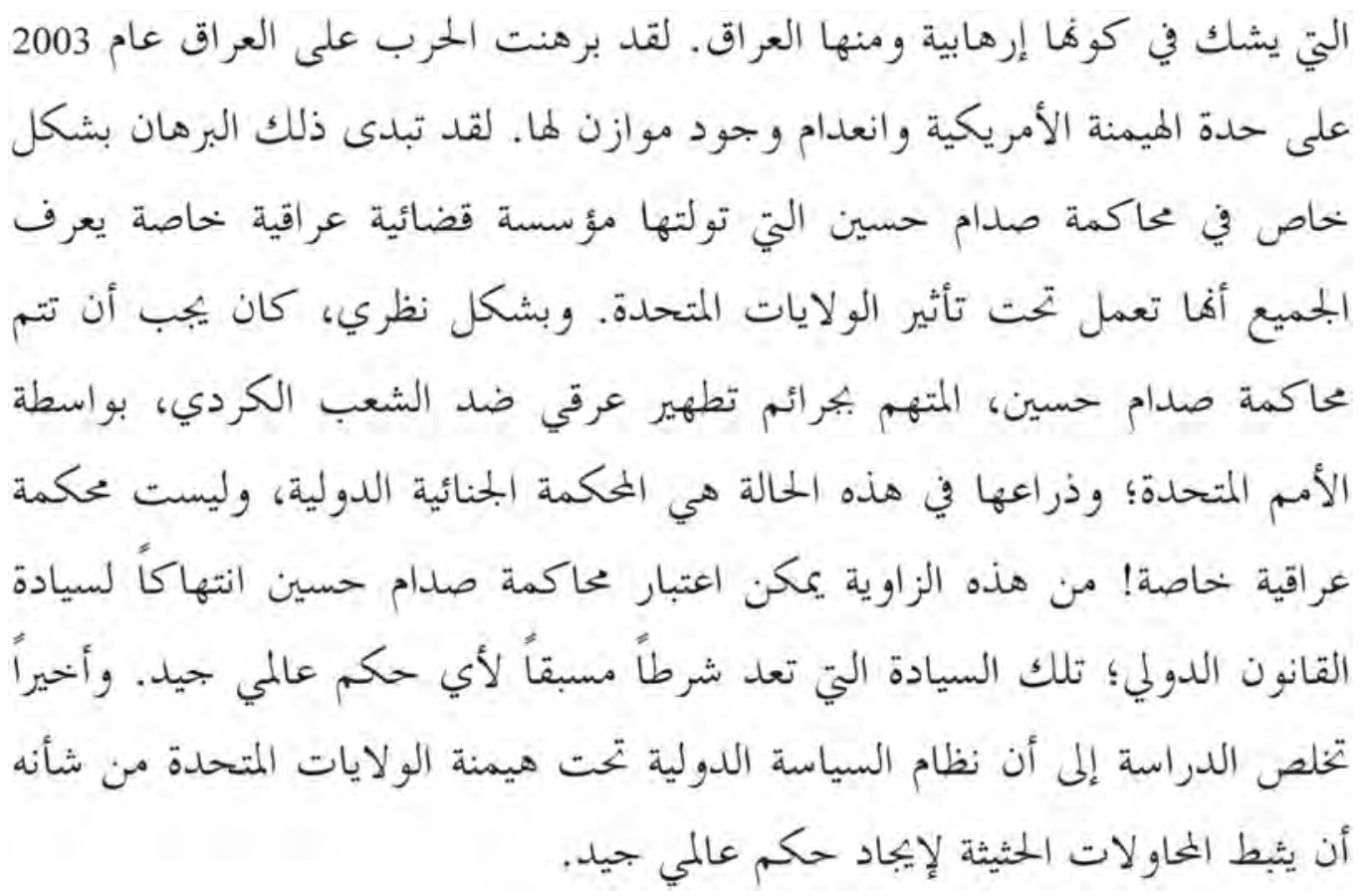

Keywords: governance, politics, hegemony, law supremacy.

\section{A. Pendahuluan}

Runtuhnya World Trade Center Amerika Serikat pada 11 September 2001 telah membuka mata para petinggi negara adidaya itu betapa keamanan dalam negeri Amerika Serikat sangat rentan terhadap ancaman dan gangguan. Hal ini bertolak belakang dengan dominasi pengaruh Amerika Serikat dalam proses politik dunia. Kekuatan Amerika Serikat dewasa ini telah menjangkau ke setiap sudut dunia, ke semua benua, ke semua negara. Kekuatan itu termanifestasikan dalam kekuatankekuatan ekonomi, budaya, ilmu pengetahuan, teknologi, senjata, maupun intelijen.

Sebagai negara adikuasa yang masih bertahan hingga saat ini pasca perang dingin, AS mempunyai andil besar dalam menentukan kelangsungan hidup negara-negara lain maupun dalam tata hubungan internasional. Keterlibatan AS dalam perubahan rezim di Irak merupakan salah satu bukti besarnya pengaruh AS. G. John Ikenberry menyatakan:

"No one disagrees that U.S. power is extraordinary. It is the character and logic of U.S. domination that is at issue in the debate over empire. The United States is not just a superpower pursuing its interest; it is a producer of world order."1

1 G. John Ikenberry, "Illusions of Empire: Defining the New American Order", dalam Foreign Affairs, Vol. 83, No. 2, March/April 2004, hal. 145. 
Sebagaimana kita ketahui pada tahun 1990-an presiden AS George H.W. Bush (Bush Sr.) pernah memproklamasikan The New World Order yang mengandung pengertian bahwa akan terbangun sebuah sistem global yang absah dan berlandaskan demokrasi. Doktrin tersebut diteruskan oleh George W. Bush (Bush), terlebih setelah tragedi WTC 11 September 2001 AS di bawah pemerintahan Bush secara tegas menyatakan bahwa segala sesuatunya di dunia ini telah berubah.

Fokus kebijakan AS diarahkan kepada perang melawan terorisme dan pelaksanaan kebijakan unilateralis. Untuk itu AS bersama Inggris dan Australia membentuk koalisi untuk mewujudkan war on terrorism, yang mencakup sanksi ekonomi serta aksi militer memerangi teroris, termasuk negara yang diduga menjadi tempat persembunyiannya.

Perang dunia baru ini merupakan hal yang sedang gencar dilakukan oleh AS. Dalam pidato yang disampaikan di depan Kongres pada tanggal 20 September 2001, George W. Bush memberikan ultimatum kepada dunia:

"Every nation in every region now has a decision to make: either you are with us or you are with the terrorist. From this day forward, any nation that continues to harbor or support terrorism will be regarded by the United States as a hostile regime."'

Dari pernyataan tersebut jelas AS menempatkan dirinya sebagai pihak yang tidak bisa berbuat salah, sedangkan negara lain yang tidak berpihak padanya disebut sebagai the axis of evil. Dalam hal ini AS menyebut Irak, Iran, dan Korea Utara adalah negara poros setan.

Irak sebagai salah satu negara yang dituduh memiliki weapons of mass destruction (WMD) ilegal dan mendukung jaringan terorisme Al-Qa'ida, merupakan target utama AS dalam war on terrorism. Pada waktu itu Irak berada di bawah pimpinan Saddam Hussein yang merupakan tokoh yang berpengaruh di kawasan Timur Tengah dan bahkan berpengaruh di dunia. Bisa dikatakan bahwa Saddam Hussein merupakan ancaman bagi AS. Hal ini ditegaskan dengan adanya pernyataan Bush pada tahun 2001 bahwa Saddam Hussein dan pemerintahannya merupakan ancaman bagi keamanan AS dan negara-negara lain.

Sebagai perwujudan war on terrorism, pada tanggal 20 Maret 2003 AS memimpin pasukan koalisi melakukan serangan udara terhadap Baghdad (ibukota Irak). Serangan tersebut menandai dimulainya Persian Gulf War of 2003 yang juga disebut dengan Operation Iraqi Freedom atau Iraq War (Perang Irak 2003).

2 Goerge W. Bush, "Freedom at war with Fear", dikutip dari: http:/ /www.whitehouse.gov/ news/releases/2001/09/20010920-8.html, diakses 5 Agustus 2007, pukul 14:38 WIB. 
Perang Irak ini merupakan perang kedua antara AS melawan Irak. Sebelumnya, koalisi dari 39 negara di bawah pimpinan AS dan PBB mengalahkan Irak dalam perang Teluk II tahun 1991. Salah satu kesepakatan yang mengakhiri Perang Teluk II yaitu bahwa Irak setuju untuk menghancurkan seluruh WMD-nya (meliputi senjata biologi, kimia, maupun nuklir termasuk fasilitas-fasilitas yang mendukung produksi senjata-senjata tersebut). Namun pada kenyataannya Irak tidak melaksanakan kesepakatan tersebut.

Setelah rezim Saddam Hussein tumbang, pasukan koalisi di bawah pimpinan AS membentuk Coalition Provisional Authority (CPA) sebagai pemerintahan sementara Irak. Aksi penyerangan dan kemudian menduduki Irak, menangkap Saddam Hussein, serta membentuk pemerintahan boneka di bawah payung CPA, AS menjanjikan segera terbentuknya kehidupan politik di Irak yang demokratis serta menjunjung tinggi prinsipprinsip HAM. Langkah AS tidak berhenti sampai terbentuknya CPA tersebut, namun AS masih memburu Saddam Hussein yang berhasil meloloskan diri. Pada 13 Desember 2003 pasukan AS akhirnya berhasil menangkap Saddam Hussein di Ad-Dawr.

Berdasarkan pasal 4 Konvensi Genewa III mengenai Perlakuan terhadap Tawanan Perang, Saddam Hussein diberi status tawanan perang (Prisoner of War/ POW) dan berdasarkan pasal 9 Konvensi Genewa III mengenai Perlakuan terhadap Tawanan Perang, POW mendapat perlindungan Komite Palang Merah Internasional (International Committee of the Red Cross / ICRC). ${ }^{3}$ Pada waktu itu Saddam Hussein belum dikenai dakwaan kriminal apapun meski disangka telah melakukan kejahatan terhadap rakyatnya sendiri selama berkuasa. ICRC juga menegaskan bahwa seorang tawanan perang yang disangka pernah melakukan tindak kejahatan tidak boleh begitu saja dibebaskan tetapi harus diadili lewat pengadilan yang sah. ${ }^{4}$

Berdasarkan mandat resolusi DK PBB No.1483 (2003) ${ }^{5}$, bangsa Irak akan mengurus masalah mereka sendiri secara otonom setelah penyerahan kedaulatan, namun pasukan koalisi akan tetap berada di sana untuk menjaga keamanan. Dengan begitu semua tawanan yang diserahkan ke Irak akan diperlakukan berdasarkan

\footnotetext{
3 "Geneva Convention Relative to the Treatment of Prisoners of War of August 12 1949", The Geneva Conventions of August 12 1949, ICRC, Geneva, hal. 76-79.

4 "Berbagai Kemungkinan Pengadilan Saddam", dikutip dari http:/ /www.suaramerdeka.com/ harian/0406/21/opi2.htm, diakses 5 Agustus 2007, pukul 14:37 WIB.

5 Berdasarkan "Coalition Provisional Authority Regulation Number 1", yang ditandatangani oleh L. Paul Bremer, dikutip http://www.cpairaq.org/ regulations/ 20030516_CPAREG_1_ The_Coalition_Provisional_Authority_pdf, diakses 13 Agustus 2007, pukul 12:45 WIB.
} 
hukum dan atau perundang-undangan Irak. Tetapi timbul perdebatan tentang bagaimana mengadili Saddam Hussein karena pada waktu itu AS belum memberi penegasan tentang siapa yang akan mengadili.

Secara teoritis pengadilan yang berwenang mengadili Saddam Hussein akan disesuaikan dengan jenis kejahatan apa yang dituduhkan padanya, sehingga hukum dapat ditegakkan. Sharon Otterman dalam tulisannya yang dimuat di Council on Foreign Relations, 17 Desember 2003, ${ }^{6}$ menjelaskan tuduhan yang akan dijatuhkan terhadap Saddam oleh pengadilan mencakup beberapa tipe kejahatan yang merupakan tindak kejahatan utama (core crimes) yang menjadi wewenang yurisdiksi International Criminal Court (ICC). Tetapi pada akhirnya AS sebagai pihak yang menangkap dan menahan Saddam Hussein memutuskan untuk menyerahkan Saddam Hussein ke Pengadilan Tinggi Kriminal Irak (the Supreme Iraqi Criminal Tribunal) atau yang lebih dikenal dengan sebutan the Iraqi Special Tribunal. Kini Saddam Hussein divonis mati atas kejahatannya dalam pembunuhan 148 orang (warga Syi'ah) di Dujail tahun 1982 yang dianggap masuk kategori tindakan genocide.

Belajar dari pengalaman pangadilan kejahatan internasional sebelumnya, seperti pengadilan terhadap para petinggi bekas Yugoslavia, Slobodan Milosevic yang diadili di International Criminal Tribunal for ex-Yugoslavia (ICTY) di the Hague, Belanda yang dibentuk pada tahun 1993 dan The International Criminal Tribunal for Rwanda (ICTR) di Arusha, Tanzania tahun 19947, pengadilan terhadap Saddam Hussein seharusnya menggunakan yurisprudensi dari pengadilan tersebut. Analogi dengan itu Saddam Hussein seharusnya diadili di International Criminal Court (ICC) atas kejahatan internasional yang didakwakan kepadanya.

Melihat fenomena proses hukum Saddam ini, nampak bahwa terjadi anomali pada proses peradilan Saddam Hussein. Lembaga ICC yang secara hukum internasional dianggap relevan untuk memproses kasus Saddam ini, ternyata tidak mendapatkan mandat suci untuk menangani masalah Saddam dari Badan Perserikatan Bangsa Bangsa, namun justru lembaga peradilan lokal yang menangani yaitu the Iraqi Special Tribunal yang disepakati oleh Amerika Serikat menangani kasus Saddam. Ironis memang, ketika Perserikatan Bangsa - Bangsa yang didaulat

6 Trias Kuncahyono, Bulan Sabit di Atas Baghdad, (Jakarta: Penerbit Buku Kompas, 2005), hal. 232-233.

7 Andari Karina Anom, "Dari Nuremberg sampai Bagdad”, Majalah Tempo Edisi 13-19 November 2006, hal. 134; Romli Atmasasmita, Kapita Selekta: Hukum Pidana Internasional, (Bandung: Putra A Bardin, 1998), hal. 12. 
sebagai organisasi internasional yang berwenang untuk memfasilitasi dalam masalah hubungan antar bangsa terkait dengan hukum internasional, pengamanan internasional, lembaga ekonomi dan perlindungan sosial, ternyata tidak mampu bersuara pada proses peradilan Saddam.

Sandiwara peradilan Saddam yang dinilai mayoritas masyarakat dunia tidak adil bahkan dianggap tragedi tersebut menyisakan pertanyaan yaitu bagaimanakah proses pencapaian good world governance dalam konteks politik internasional ketika Imperium Amerika tetap menjadi hegemon dalam politik antar bangsa? Dan bagaimana sebetulnya proses pencapaian tatanan masyarakat dunia yang berkeadilan sosial dan tidak lagi mengedepankan perang atau penyelesaian fisik sebagai solusi dari suatu permasalahan?

\section{B. Good World Governance dan Politik Internasional}

Konsep Good Governance pada awalnya dirujuk dari konsep Good Corporate Governance (GCG) yang merupakan definisi teknis dalam praktik ekonomi yang telah menjadi bahasa pemerintahan. Good governance dapat diartikan sebagai suatu proses yang yang mengarahkan terciptanya kekuatan dan kewenangan yang merata dalam seluruh elemen masyarakat untuk mempengaruhi keputusan dan kebijakan yang berkaitan dengan kehidupan publik serta seluruh upaya pembangunan sosial dan ekonomi masyarakat. Oleh karena itu good governance mensyaratkan adanya proses yang berkelanjutan untuk mengakomodasi dan memediasi konflik - konflik kepentingan dalam struktur masyarakat, sehingga dapat memperoleh kesepakatan bersama. ${ }^{8}$

Governance dalam perspektif penyelenggara negara (good government governance, good governance) adalah pelaksana kewenangan politik, ekonomi, dan administrasi untuk mengelola urusan bangsa, mekanisme, proses, serta hubungan antar warga negara dan kelompok kepentingan. Hal ini sebagai jaminan terlaksananya hak dan kewajiban warga serta menengahi atau memfasilitasi jika terjadi perbedaan kepentingan. Dalam tulisan ini istilah GCG akan dideskripsikan sebagai konsep yang menjelaskan tatanan kehidupan politik antar bangsa sekarang ini yang selanjutnya akan disebut good world governance.

8 Ardiansyah Samsura, Participatory Planning, Good Governance, and Civil Society, Forum Pengembangan Partisipasi Masyarakat (FPPM), 2002, sebagaimana dikutip oleh Amir Faisol, "Agama Dan Penyelenggaraan Pemerintahan Yang Baik", dalam Millah, Vol V, No. 2, (Yogyakarta: Magister Studi Islam UII, 2006), hal. 157 
Penyelenggara negara mempunyai tiga pilar yaitu economic governance, political governance, dan administrative governance. Economic governance meliputi proses pembuatan keputusan yang mempengaruhi ekonomi negara baik langsung maupun tidak langsung. Political governance merujuk pada proses pembuatan keputusan dan penerapan kebijakan negara secara absah, baik di tingkat legislatif, eksekutif, dan judikatif. Sedangkan administrative governance merupakan sistem penerapan kebijakan yang memungkinkan sektor publik berjalan efisien, tidak memihak, akuntabel, serta terbuka.

Untuk mencapai suatu tatanan good governance atau dalam hal ini good world governance, maka paling tidak ada delapan karakteristik yang harus dapat dipenuhi oleh Negara-negara bangsa di dunia ini, yaitu: participatori, konsensus, akuntabel, transparan, responsif, efektif and efisien, adil dan inklusif serta mematuhi peraturan hukum yang berlaku. ${ }^{9}$ Dari syarat-syarat untuk mencapai good governance tersebut tampak jelas bahwa untuk mencapai suatu tatanan good governance dalam konteks politik internasional atau good world governance secara total memanglah sangat sulit, namun bukan tidak mungkin jika setiap negara bangsa di dunia ini mempunyai komitmen untuk mewujudkannya.

Selanjutnya mengenai konsep politik internasional. Politik internasional merupakan hubungan antara satu negara dengan negara lain, atau dengan kata lain politik internasional adalah hubungan internasional yang aktor pelakunya adalah Negara, dan isu yang dibahas bersifat bigh politics. ${ }^{10}$

\section{Amerika: Hegemoni Sebuah Imperium}

1. Amerika Serikat di Bawah George W. Bush

Jabatan kepresidenan Amerika Serikat (AS) merupakan salah satu yang paling berkuasa di dunia. Seperti yang tercantum dalam Konstitusi AS, presiden sebagai pejabat federal bertugas terutama untuk bertanggung jawab terhadap hubungan AS dengan negara-negara lain. ${ }^{11}$

9 "What Is Good Governance", dikutip dari http://www.unescap.org/pdd/prs/ ProjectActivities/ Ongoing/gg/governance.asp., diakses 16 Agustus 2007, pukul 14:37 WIB.

10 Disarikan dari: David A.Lake and Patrick M. Morgan, Regional Order Building Security in a New World, United States of America: Pensylvania State University Press, 1992), hal. 125-139.

11 Garis Besar Pemerintahan Amerika Serikat, Office of International Information Programs, United States Department of State, 2000, hal. 53-54. 
Zbigniew Brzezinski berpandangan bahwa kekuatan AS adalah penjamin stabilitas global, namun masyarakatnya mendorong gelagat sosial dunia yang memporakporandakan kedaulatan nasional. Pandangan yang lain menunjukkan bahwa AS mempengaruhi militerisasi politik internasional sebagai agen pengekspor senjata terbesar di dunia. ${ }^{12}$

Tahun 2004 merupakan masa kepemimpinan Bush yang ke-2 sebagai presiden AS. Sebelumnya ia adalah presiden AS ke-43 yang memimpin pada tahun 2001. Bush yang berasal dari Partai Republik berhasil mengalahkan Al-Gore dari Partai Demokrat dengan kemenangan pada electoral votes tetapi kalah pada popular votes.

Pemilihan pada tahun 2000 tersebut merupakan kejadian ke-4 dalam sejarah AS, dimana pemenang memperoleh lebih sedikit popular votes daripada lawannya. ${ }^{13}$ Orientasi politik luar negeri AS di bawah Bush yang berasal dari Partai Republik cenderung ke high politics dan berhaluan realis dengan asumsi tindak kekerasan dilawan dengan kekerasan. Hal ini disebabkan karena dalam bidang politik luar negeri Partai Republik mendukung superioritas militer. ${ }^{14}$

2. Politik Luar Negeri Amerika Serikat Pasca tragedi 11 September 2001

Belum genap satu tahun Bush menjadi presiden, AS menghadapi major crisis pada 11 September 2001(9/11), yaitu serangan teroris terburuk dalam sejarah AS yang terjadi di World Trade Center di New York dan Pentagon Building dekat Washington, D.C. Pemerintah AS kemudian menyatakan bahwa organisasi Al-Qa'ida di bawah pimpinan Osama bin Laden bertanggung jawab atas serangan tersebut.

Berikut merupakan beberapa kebijakan penting yang diterapkan AS di bawah Bush dalam politik luar negerinya pasca tragedi $9 / 11::^{15}$

12 Peter J. Katzenstein, "Conclusion: National Security in a Changing World", dalam Peter J. Katzenstein (ed.), The Culture of National Security: Norm and Identity in World Politics, dalam Suzie Sudarman, "Norma-norma, Identitas, dan Politik Luar Negeri AS Periode ke-2 Bush", Jurnal Studi Amerika, Vol. X No. 2, Juli-Desember, (Jakarta: Pusat Kajian Wilayah Amerika Universitas Indonesia, 2005), hal. 42.

13 Tiga orang sebelumnya yang memenangkan jabatan kepresidenan tanpa memenangkan popular votes adalah John Quincy Adams (1824), Rutherford B. Hayes (1876), dan Benjamin Harrison (1888). Selain itu terpilihnya Bush merupakan kejadian ke-2 dimana seorang anak dari mantan presiden menjadi seorang presiden. Ayah Bush, George Herbert Walker Bush (Bush Sr.), menjadi presiden AS sejak 1989 hingga 1993. Pasangan ayah dan anak sebelumnya adalah John Adams yang memimpin sejak 1797 hingga 1801 dan John Quincy Adams yang memimpin sejak 1825 hingga 1829, dalam Bush, George Walker (Article Updates), The World Book Multimedia Encyclopedia (C) 2005 World Book, Inc. 233 North Michigan Avenue Suite 2000 Chicago, Illinois 60601.

14 Bambang Cipto, Politik dan Pemerintahan Amerika, (Yogyakarta: Lingkaran, 2003), hal. 60.

15 Disarikan dari “Bush's Administration", The World Book Multimedia Encyclopedia () (2005), World Book, Inc. 233 North Michigan Avenue Suite 2000 Chicago, Illinois 60601. 
a. Military action. AS bersama Inggris dan Australia membentuk koalisi untuk mewujudkan war on terrorism, yang mencakup sanksi ekonomi serta aksi militer memerangi teroris, termasuk negara yang diduga menjadi tempat persembunyiannya. Serangan tersebut juga menjadikan politik luar negeri AS di masa Bush terlihat lebih agresif.

b. Homeland Security. George W. Bush membentuk Department of Homeland Security yang bertugas memantau dan mengatur pertahanan nasional AS untuk memerangi serangan teroris. Selain itu Bush menaikkan anggaran untuk pasukan militer dan homeland security dengan mengurangi pengeluaran di sektor lain, misalnya program-program sosial.

c. Arms Control. Pada 13 Juni 2002 AS resmi menarik diri dari Antiballistic Missile Treaty, sebuah pakta yang mengatur pembatasan sebuah negara dalam menggunakan sistem pertahanan misil. Dengan keluar dari perjanjian tersebut AS dapat mengembangkan antimissile system untuk melindungi negara dari kemungkinan serangan teroris dikemudian hari.

d. War against Iraq. Sejak Saddam Hussein menolak untuk mengijinkan PBB melakukan inspeksi di Irak, AS menyebut rezim Saddam sebagai " $a$ grave and gathering danger" dan bahkan setelah kejadian 9/11 Bush menuduh Irak mendukung organisasi teroris internasional (Al-Qa'ida). Dengan dalih keberadaan WMD dan keterlibatan Irak dalam terorisme, AS melancarkan Perang Irak 2003 walaupun kedua alasan tersebut tidak terbukti. Namun Bush mempertahankan keputusannya tersebut dengan menegaskan bahwa invasi tersebut sebagai preemptive action karena Saddam Hussein adalah diktator kejam yang harus ditumbangkan dari kekuasaannya.

\section{Perang Irak 2003}

Berbicara mengenai Perang Irak, maka tidak dapat dilepaskan dari lahirnya National Security Strategy of the United States of America (NSS 2002). NSS 2002 adalah kumpulan pidato Bush di hadapan Kongres AS yang telah dipublikasikan oleh Gedung Putih pada tanggal 22 September 2002. NSS 2002 menjadi strategi utama keamanan AS pasca tragedi 9/11 dan merupakan pedoman dari kebijakan politik luar negeri AS dalam masa teror. Dalam pengantar NSS tersebut, Bush secara tegas menyebutkan bahwa: 
"Enemies in the past needed great armies and great industrial capabilities to endanger America. Now, shadowy networks of individuals can bring great chaos and suffering to our shores for less than it costs to purchase a single tank ...the events of September 11, 2001, taught us that weak states, like Afghanistan, can pose as great a danger to our national interests as strong states" 16

Pernyataan Bush tersebut menunjukkan bahwa strategi AS tidak lagi menyerang negara-negara yang mereka curigai pada era Perang Dingin. Namun lebih banyak melihat ancaman dalam "bayangan" yaitu kelompok teroris. Strategi tersebut seakanakan juga menyatakan bahwa Bush akan memerangi terorisme menurut caranya sendiri dengan mengabaikan hukum internasional.

Setiap presiden AS memerlukan dukungan Kongres dalam menjalankan politik luar negeri khususnya yang berkaitan dengan pelaksanaan perang. Konstitusi AS menyebutkan bahwa yang paling berwenang menyatakan perang (declarations of war) adalah Kongres. Dengan demikian Kongres memang secara konstitusional memiliki otoritas dalam bidang politik dan keamanan nasional. ${ }^{17}$

Perang Irak 2003 terjadi atas tuduhan AS terhadap Irak bahwa negara tersebut mempunyai dan mengembangkan WMD, serta mendukung Al-Qa'ida. Bahkan Bush menyebut rezim Saddam sebagai "a grave and gathering danger". Didasarkan atas tuduhan tersebut AS bisa melancarkan serangan militer terhadap Irak sebagaimana yang disebutkan dalam NSS 2002, bahwa AS bisa melakukan serangan terhadap negara yang diduga akan mengancam keamanan nasional AS (preemptive action).

Untuk membuat kebijakan luar negeri tidaklah mudah bagi presiden AS, ada beberapa prosedur yang harus terlebih dahulu dilewati oleh presiden AS. Yang paling utama adalah persetujuan Kongres, karena dalam pemerintahan AS kekuasaan legislatif relatif lebih besar daripada eksekutif, karena itu Kongres memegang kendali besar atas terlaksana atau tidaknya sebuah kebijakan luar negeri yang diusulkan presiden. Langkah yang diambil Bush adalah meminta Kongres untuk mengesahkan resolusi yang mengijinkan Bush untuk menggunakan kekuatan militer terhadap Irak. Pada November 2002 Kongres akhirnya menyetujui resolusi tersebut. ${ }^{18}$

16 President of the United States, The National Security Strategy of the United States of America (2002)

17 Bambang Cipto, Politik Pemerintahan Amerika..., hal. 212.

18 Disarikan dari "Bush's Administration", The World Book Multimedia Encyclopedia () (2005), World Book, Inc. 233 North Michigan Avenue Suite 2000 Chicago, Illinois 60601. 
Sebagian besar warga AS pada saat itu mendukung keputusan Bush melancarkan serangan terhadap Irak. Namun kebijakan Bush tersebut juga mendapat kritikan dari masyarakat internasional yang mengatakan bahwa AS melanggar hukum internasional dengan menginvasi negara lain yang dianggap tidak menunjukkan ancaman. Namun Bush mempertahankan keputusannya tersebut dengan menegaskan bahwa invasi tersebut sebagai preemptive action. Sehingga dapat dikatakan bahwa Perang Irak 2003 merupakan implementasi yang paling nyata dari dua prinsip utama doktrin keamanan terbaru AS, NSS 2002, yaitu preemptive action dan unilateralisme.

Pada kenyataannya keinginan AS melancarkan invasi sebagai perwujudan war on terrorism tercapai tanpa persetujuan DK PBB. Pada tanggal 20 Maret 2003 AS memimpin pasukan koalisi melakukan serangan udara terhadap Baghdad (ibukota Irak). Serangan tersebut menandai dimulainya Persian Gulf War of 2003 yang juga disebut dengan Operation Iraqi Freedom atau Iraq War (Perang Irak 2003). Hal ini memberi peringatan kepada masyarakat internasional bahwa AS mampu melancarkan aksi militer tanpa harus menunggu keputusan dari PBB dan atau dari negara manapun.

\section{Peradilan Saddam Hussein dan Tragedi Good World Governance}

1. Pengaruh Amerika Serikat dalam Proses Peradilan Saddam Hussein

Ditangkapnya Saddam Hussein menimbulkan perdebatan baru di kalangan masyarakat internasional. Hal ini timbul karena adanya keharusan bagi pasukan koalisi di bawah pimpinan Amerika Serikat (AS) untuk menetapkan status hukum Saddam Hussein, menetapkan jenis kejahatan yang akan dituduhkan kepada Saddam Hussein, dan menetapkan proses hukum yang akan dilalui oleh Saddam Hussein.

Terkait status hukum Saddam, paling tidak ada tiga kemungkinan mengenai status hukum Saddam Hussein, yaitu sebagai tawanan perang, sebagai internee (tawanan), atau sebagai tahanan politik. ${ }^{19}$ Status sebagai tawanan perang dapat dikenakan kepada Saddam Hussein apabila pasukan koalisi memandang Saddam Hussein sebagai seorang petempur yang tertangkap oleh pasukan lawan dalam suatu

19 Disarikan dari Andi Widjajanto, "Komplikasi Hukum Tertangkapnya Saddam Hussein”, dikutip melalui http://www.kompas.com/kompas-cetak/0312/17/Jendela/744944.htm diakses 15 Agustus 2007, pukul 15:18 WIB. 
sengketa bersenjata. ${ }^{20}$ Namun kecil kemungkinan Saddam Hussein ditetapkan sebagai tawanan perang, sebab berdasarkan Pasal 118 dan Pasal 119 Konvensi Geneva, pasukan koalisi harus segera melepaskan Saddam Hussein jika perang dinyatakan selesai. ${ }^{21}$

Status internee diberikan kepada individu atau kelompok dari satu pihak konflik yang tinggal atau berada dalam suatu wilayah yang dikuasai oleh pihak lawan yang tertangkap oleh penguasa administratif atau militer pihak lawan. Jika diberikan status internee, Saddam Hussein akan ditempatkan di suatu tempat yang jauh dari bahaya perang dan dapat dikunjungi oleh kerabat dan International Committee of the Red Cross (ICRC). Status ini bersifat sementara, bergantung pada ada tidaknya kemungkinan internee dijadikan tahanan. Sedangkan status tahanan politik dapat diberikan jika Saddam Hussein dipandang sebagai individu yang akan dikenai proses hukum karena dituduh melakukan kejahatan internasional.

Penetapan status hukum Saddam Hussein terkait erat dengan jenis kejahatan yang dituduhkan kepadanya. Saddam Hussein dapat dituduh melanggar Konvensi IV Den Haag 1907 mengenai Hukum dan Kebiasaan Perang di Darat. ${ }^{22}$ Secara spesifik, Saddam Hussein dapat dikenai pasal-pasal tentang kejahatan perang dan kejahatan terhadap kemanusiaan.

Sedangkan berdasarkan Statuta Roma, Saddam Hussein dapat dikenai tuduhan atas kejahatan internasional, paling tidak pada tiga bentuk. Pertama, Saddam Hussein dapat dikenai Pasal 6 Statuta Roma dengan tuduhan melakukan pemusnahan (genocide) terhadap suku minoritas Kurdi. Kedua, kejahatan atas kemanusiaan (crimes against humanity) yang merupakan yurisdiksi ICC menurut Pasal 7 Statuta Roma, mengingat selama pemerintahannya terjadi pelanggaran berat hak asasi

20 Berdasarkan pasal 4 Konvensi Genewa III mengenai Perlakuan terhadap Tawanan Perang, Saddam Hussein diberi status tawanan perang (Prisoner of War/ POW) dan berdasarkan pasal 9 Konvensi Genewa III mengenai Perlakuan terhadap Tawanan Perang, POW mendapat perlindungan Komite Palang Merah Internasional (International Committee of the Red Cross / ICRC) dalam "Geneva Convention relative to the Treatment of Prisoners of War of August 121949 ", The Geneva Conventions of August 12 1949, Geneva: International Committee of the Red Cross, hal. 76-79.

21 Dalam "Section II: Release and Repatriation of Prisoners of War at the Close and Hostilities" Article 118 and 119, "Geneva Convention relative to the Treatment of Prisoners of War of August 12 1949”, Ibid., hal. 123-125.

22 Konvensi IV Den Haag (1907) mengenai Hukum dan Kebiassan Perang di Darat yang judul lengkapnya adalah Convention Respecting to the Laws and Customs of War on Land merupakan penyempurnaan dari Konvensi II Den Haag (1899) mengenai Hukum dan Kebiasaan Perang di Darat, dalam Arlina Permanasari et.al. (1999), Pengantar Hukum Humaniter, International Committee of the Red Cross, Jakarta, hal. 22-26 
manusia (HAM). Ketiga, dikenai Pasal 8 Statuta Roma tentang kejahatan perang (war crimes) dengan tuduhan telah terjadi pelanggaran terhadap hukum perang, terutama Konvensi Geneva.

a. Alternatif Proses Peradilan Saddam Hussein

Ada beberapa ide yang muncul mengenai cara mengadili Saddam Hussein, tetapi banyak pengamat berpendapat bahwa kecenderungan yang mungkin terjadi adalah pengadilan atas Saddam Hussein yang dipoles AS, namun dikemas atas nama Irak. ${ }^{23}$

Bila Saddam Hussein dituntut berdasarkan salah satu atau ketiga bentuk kejahatan internasional tersebut, ada sejumlah pengadilan yang berwenang mengadilinya. Pelaksanaan yurisdiksi oleh pengadilan didasarkan yurisdiksi yang berlaku bagi kejahatan internasional, yaitu yurisdiksi universal. Yurisdiksi universal pada dasarnya memberi kewenangan pengadilan mana pun untuk mengadili pelaku kejahatan internasional. Sempat ada usulan dari beberapa politisi AS agar Saddam dibawa ke AS dan diadili oleh pengadilan militer AS. Namun jika Saddam Hussein diadili di AS akan menjadi penyangkalan atas ide formal AS bahwa Irak adalah pengelola di negaranya sendiri setelah penyerahan kedaulatan dari Coalition Provisional Authority (CPA) kepada Iraqi Governing Council (IGC).

Pilihan lain adalah menyerahkan Saddam Hussein ke International Criminal Court (ICC) yang berkedudukan di Den Haag yang memang memiliki yurisdiksi untuk mengadili kejahatan terhadap kemanusiaan, kejahatan perang, dan pembunuhan massal. Namun, AS tidak setuju dengan ide tersebut, sebagian alasannya karena Irak tidak turut meratifikasi ICC. Alasan terbesar adalah ICC tidak dapat menjatuhkan eksekusi hukuman mati. Selain itu penolakan AS terhadap ICC berkaitan dengan kepentingan unilateralis AS.

Untuk mengaktifkan ICC, bisa menggunakan Pasal 13, Pasal 14, dan Pasal 15 Statuta Roma 1998. Pasal 13 memberikan kewenangan bagi Dewan Keamanan PBB untuk menyerahkan Saddam Hussein kepada ICC. Pasal 14 memungkinkan suatu negara (dalam hal ini AS, Irak, atau salah satu negara koalisi) untuk menyeret Saddam Hussein ke ICC. Pasal 15 membuka peluang bagi jaksa penuntut dari ICC untuk menangani kasus Saddam Hussein.

23 "Arah Pengadilan Saddam: Sentuhan AS, tetapi Dikemas atas Nama Irak", Kompas, Kamis, (18 Desember 2003), dikutip dari http://www.kompas.com/kompascetak/0312/18/sorotan/ 753159.htm, diakses 16 Agustus 2007, pukul 12:08 WIB. 
Proses hukum yang akan dijalani oleh Saddam Hussein akan menentukan apakah AS masih berniat mengupayakan multilateralisme yang akan memperkuat masyarakat antar bangsa dan memperkuat prinsip-prinsip hukum kemanusiaan antarbangsa yang tertuang dalam berbagai konvensi antar bangsa, atau sebaliknya AS akan mengambil langkah yang tidak mencerminkan komitmen ke arah komunitas dan hukum kemanusiaan antar bangsa.

Terlepas dari pengadilan yang memiliki kewenangan untuk mengadili Saddam Hussein, yang menjadi faktor penentu ke mana ia diadili adalah sikap AS. Ini mengingat saat ini negara yang menahan Saddam Hussein secara fisik adalah AS. Sikap ini tidak semata-mata didasarkan pada pertimbangan yuridis, tetapi lebih ditekankan pada pertimbangan politis.

Pada akhirnya pilihan AS tertuju pada alternatif lain soal proses pengadilan atas Saddam Hussein, yang proses persiapan dan pembicaraannya sudah lebih maju, yaitu mengadili Saddam di Iraqi Special Tribunal (IST) yang dijuluki sebagai solusi domestik. IST dibentuk oleh $\mathrm{CPA}^{24}$ dengan menyusun The Statute of the Iraqi Special Tribunal yang mulai berlaku pada 10 Desember 2003. Pilihan AS tersebut tidak serta merta diterima oleh kalangan internasional. Hal ini didasarkan fakta bahwa kapasitas para ahli hukum Irak tidak memadai untuk mengadili kasus sebesar Saddam. Sedangkan alasan lain adalah, meski diadili di Irak oleh pengadilan khusus di Irak, pengadilan itu tidak bisa melepaskan diri dari pengaruh AS.

b. Pengaruh Amerika Serikat terhadap the Iraqi Special Tribunal

Secara politis mendirikan Iraqi Special Tribunal (IST) adalah pilihan yang paling masuk akal bagi AS, walaupun secara hukum masih ada pilihan lain. Kaitannya dengan hal ini, AS sebagai kekuatan pendudukan Irak, dengan seksama memperhatikan pengorganisasian dan penerapan peraturannya, tetapi AS mengatur sedemikian rupa sehingga tetap bisa dianggap bahwa IGC-lah yang bertanggung jawab bagi pendirian IST, termasuk pengangkatan para pejabat dan stafnya. ${ }^{25}$

Walaupun begitu, pemerintahan George W. Bush (Bush) telah menegaskan bahwa IST sepenuhnya dikendalikan oleh Irak. Hal ini disampaikan oleh juru bicara

24 Berdasarkan "Coalition Provisional Authority Order Number 48: Delegation of Authority Regarding an Iraqi Tribunal”,CPA/ORD/9 Dec 2003/48 (2003) (IST Statute), IST.

25 "Tribunal Kejahatan terhadap Kemanusiaan di Irak", dikutip dari http://www.ranesi.nl / arsipaktua/timurtengah/irak/tribunal_irak.html diakses 12 Juli 2007, pukul 20:35 WIB. 
White House, Scott McClellan yang berkata, 'Saddam Hussein is facing Iraqi justice". Tetapi dasar hukum yang digunakan untuk mengadili Saddam Hussein dibuat di bawah pengawasan CPA yang dipimpin oleh AS. ${ }^{26}$

Menurut laporan penilaian PBB dalam World Bank - UNDG Legal Needs Assessment Mission to Iraq, August 2003, Human Rights Watch (HRW) menyimpulkan bahwa para hakim, jaksa, dan pembela dalam IST tidak mampu menjalankan proses peradilan yang rumit seperti proses Saddam Hussein karena belum memiliki pengetahuan yang memadai.

Berdasarkan fakta tersebut di atas IST akan sangat bergantung pada bantuan luar negeri. ${ }^{27}$ Selain bergantung dalam hal sumber daya manusia, IST juga masih membutuhkan bantuan luar dalam hal dana. Pada kenyataannya AS, sebagai pemimpin pasukan koalisi yang menduduki Irak, telah menyediakan dana sebesar 75 juta dolar AS pada tahun 2003 untuk membiayai investigasi dan pengadilan terhadap Saddam Hussein dan rezimnya. Dana tersebut bahkan telah diperbesar mencapai 128 juta dolar AS. ${ }^{28}$ Dana tersebut diberikan AS melalui U.S. Embassy's Regime Crimes Liaison Office (RCLO). Walaupun AS menyatakan bahwa peran mereka hanya sebagai peran pendukung dalam Statuta IST, Laporan Tiga Bulanan RCLO kepada Kongres AS menunjukkan bahwa staf RCLO sebanyak lebih dari lima puluh orang telah berperan penting dalam berbagai aspek dalam kinerja IST, termasuk pembangunan ruang pengadilan, memimpin penyelidikan, mewawancarai tahanan, memeriksa dokumen-dokumen yang disita dan mempersiapkan bukti-bukti, dan pelatihan terhadap staf IST.

Selama lebih dari satu tahun, AS secara aktif telah berupaya mendampingi IST dari pada negara lain ataupun PBB, untuk mendukung legitimasi IST dan menghindari pernyataan bahwa pengadilan tersebut didominasi oleh AS. Tetapi IST menemui kesulitan besar dalam memperoleh bantuan dari negara-negara lain.

26 Dikutip dari http://www.globalpolicy.org/intljustice/tribunals/iraq/2005/1019fairness.htm diakses 14 Juli 2007, pukul 16:11 WIB.

27 Fakta tersebut dilaporkan kepada Kongres AS, bahwa "Currently, Iraq lacks the professional and technical investigative and judicial expertise to [prosecute crimes against humanity and war crimes] on its own, and therefore needs Coalition assistance": Department of State, Quarterly Update to Congress: Section 2207 Report on Iraq Relief and Reconstruction (Januari 2004), hal. 43, dalam The Former Iraqi Government on Trial, A Human Right Watch Briefing Paper, October 16, 2005, hal. 17, dikutip dari http://hrw.org/backgrounder/mena/iraq1005/iraq1005.pdf diakses 27 Juli 2007 pukul 12:56 WIB.

28 Berdasarkan Department of State, Quarterly Update to Congress: Section 2207 Report on Iraq Relief and Reconstruction (Januari 2004), hal. 43 dan (April 2005), hal. 30, dalam Ibid. 
Kesulitan tersebut disebabkan oleh penerapan hukuman mati di IST, situasi keamanan Irak yang tidak terjamin, dan juga karena IST didominasi oleh AS. ${ }^{29}$ Fakta bahwa IST sangat bergantung pada dukungan dan bantuan dana dari AS telah mengurangi kewibawaan IST. Menurut the New York Times, RCLO bahkan menyertakan pengacara dan ahli hukum internasional dari negara anggota pasukan koalisi, terutama Inggris dan Australia, yang merupakan "the real power bebind the tribunal".

2. Keuntungan Amerika Serikat dalam Proses Peradilan Saddam Hussein di Iraqi Special Tribunal (IST)

Keputusan AS memberikan kewenangan kepada IST untuk mengadili Saddam Hussein dibuat berdasarkan rasionalitas, yaitu menggunakan pertimbangan untungrugi. Tentu saja dalam hal ini AS akan diuntungkan daripada menyerahkan Saddam Hussein kepada ICC. AS akan mendapatkan keuntungan politis jika memberikan kewenangan kepada IST untuk mengadili Saddam Hussein.

a. Kepentingan Politik AS dalam the Iraqi Special Tribunal

Dengan memberikan kewenangan terhadap IST sebagai peradilan yang mengadili Saddam Hussein, AS berkepentingan untuk menyeimbangkan gagasan unilateralisme dan multilateralisme. Pada satu sisi AS ingin tetap memainkan perannya selaku pemimpin di dalam institusi-institusi internasional yang bersifat multilateral, namun pada sisi yang lain AS juga ingin mempertahankan kondisi dimana ia bisa memiliki kebebasan untuk melakukan tindakan unilateral.

Dalam hal ini AS menginginkan kontrol penuh terhadap IST sehingga Perhimpunan Bangsa-Bangsa (PBB) sekalipun tidak bisa campur tangan di dalamnya, sehingga AS bisa mempertahankan kebebasan unilateralnya. Hal ini menjadikan mekanisme peradilan IST lebih mudah dipengaruhi oleh AS dari pada melalui ICC dalam memutuskan masalah Saddam mengingat pemerintahan Irak pasca runtuhnya rezim Saddam adalah pemerintahan boneka di bawah pengaruh AS.

Lembaga peradilan ini memberlakukan kembali hukuman mati, berarti Saddam Hussein bisa divonis mati sehingga pemerintahan boneka buatan AS di Irak dapat terwujud. Walaupun begitu AS bisa lepas tangan atas keputusan peradilan, karena Saddam Hussein diadili oleh lembaga peradilan nasional Irak. Sehingga memberikan kewenangan kepada IST adalah keputusan yang paling representatif daripada diserahkan ke ICC.

29 Data diperoleh dari komentar kepala RCLO Greg Kehoe (2005), “A Slow Search for Justice in Iraq", Legal Times, 24 January; Department of State, Quarterly Update to Congress: Section 2207 Report on Iraq Relief and Reconstruction (Juli 2004) dalam Ibid. 
Sedangkan berdasarkan pengalaman, proses peradilan di ICC akan berjalan lama. Selain itu mekanisme peradilannya sulit (bahkan tidak bisa) dipengaruhi oleh AS. Hal ini tentu saja akan memasung kebebasan AS untuk bertindak secara unilateral. AS juga khawatir Statuta Roma akan memunculkan international prosecutor dengan kewenangan besar dan bertindak tanpa persetujuan negara maupun DK PBB sehingga warga AS bisa diadili di ICC. Alasan lain adalah AS tidak menginginkan pengadilan internasional karena jika Saddam Hussein diadili oleh ICC akan mengungkit relasi antara rezim Saddam Hussein dengan pemerintahan AS di masa lalu.

b. Sikap Oposisi Amerika Serikat terhadap ICC

AS beranggapan bahwa hukum internasional mengikat negara hanya secara sukarela. Bila kepentingan negara terlanggar oleh hukum internasional, maka negara itu boleh membuat undang-undang untuk melindungi kepentingannya dan mengesampingkan hukum internasional. Yang menang adalah undang-undang nasional, sedangkan hukum internasional tetap dikalahkan, walaupun hukum internasional tersebut telah disetujui oleh negara bersangkutan di masa lalu.

Penentangan AS terhadap ICC dimulai sejak awal masuknya Partai Republik dan George W. Bush (Bush) ke Gedung Putih. Penolakan tersebut disampaikan dalam pidato duta besar AS di PBB pada pertengahan 2001. ${ }^{30}$ Padahal di bawah pemerintahan Bill Clinton AS masih menandatangani traktat pendirian ICC. Tapi Bush mencabut tanda tangan itu, ia menolak segala bentuk pengawasan hukum internasional terhadap tentara AS, karena menganggap hal ini hanya akan membatasi gerak AS. Pemerintahan Bush khawatir ICC hanya akan mengadili pasukan AS semata-mata karena pertimbangan politik. Lebih dari itu AS menolak untuk mengakui wibawa sebuah pengadilan internasional di atas pengadilannya sendiri.

Alasan utama yang diberikan oleh AS kenapa mereka "menentang" Statuta Roma adalah bahwa ICC akan dapat menerapkan yurisdiksinya atas peristiwa yang terjadi di dalam wilayah sebuah negara yang telah menerima yurisdiksi ICC. AS mendesak agar ICC hanya dapat menerapkan yurisdiksinya jika negara dimana tersangka adalah warganya telah menerima yurisdiksi.

Alasan lain yang dikemukakan AS dalam penentangannya terhadap ICC antara lain: ${ }^{31}$

30 Eddy Djunaedi, “Mengapa AS Tidak Setuju dengan Statuta ICC?”, Varia Peradilan, Majalah Hukum Tahun XVI No. 184, 1998.

31 Disampaikan oleh Ambassador Scheffer (PBB) tanggal 23 Juli 1998 di depan komisi luar negeri senat AS, dalam Ibid. 
Pertama, pada saat dihadapkan pada ide pembentukan ICC, sebenarnya AS berkepentingan untuk menyeimbangkan gagasan unilateralisme dan multilateralisme. Kepentingan unilateral AS yaitu untuk bisa memiliki kebebasan untuk melakukan tindakan unilateral, seperti yang dilakukannya saat melakukan invasi terhadap Irak pada tahun 2003, tanpa memandang eksistensi PBB sebagai sebuah lembaga internasional. Sedangkan kepentingan multilateral AS yaitu ingin tetap memainkan perannya selaku pemimpin di dalam institusi-institusi internasional yang bersifat multilateral, seperti PBB, NATO, dan lembaga-lembaga internasional lainnya dimana AS memiliki posisi sebagai pemimpin.

Tuntutan semacam itu tidak terlalu menonjol dalam pembentukan mahkamahmahkamah yang bersifat ad hoc (dalam hal ini adalah IST) yang merupakan wujud dari kebebasan unilateralnya. Apabila AS memberikan kewenangan kepada ICC yang bersifat institutionalized dan permanen untuk mengadili Saddam Hussein, AS khawatir bahwa hal itu akan memasung kebebasannya untuk bertindak secara unilateral.

Kedua, meskipun AS tidak mendukung pelaku kejahatan internasional, tampaknya merupakan kebijakan yang jelas dari pihak AS untuk tidak membiarkan warganya diadili oleh suatu mahkamah internasional. Hal ini didasarkan alasan bahwa mahkamahmahkamah yang bersifat ad hoc dan memiliki yurisdiksi teritorial yang terbatas akan bisa dikontrol untuk tidak mencakup warga AS. Sebaliknya kontrol seperti itu akan lebih sulit dilakukan dalam institusi yang bersifat permanen dan universal seperti ICC.

Ketiga, kekhawatiran AS tentang kemungkinan bahwa Statuta Roma akan memunculkan jaksa penuntut umum yang independen (independent prosecutor) dengan kewenganan yang besar. Padahal Statuta Roma tidak memberikan kepada Penuntut Umum ICC untuk melakukan penyelidikan independen tarhadap otoritas nasional, melainkan hanya memberinya wewenang untuk meminta kerjasama dan bantuan dari State Party sesuai dengan Statuta dan sesuai juga dengan prosedur nasional masing-masing State Party. Persyaratan untuk bekerjasama memalui prosedur nasional ini membuka kesempatan bagi pemerintah State Party untuk melakukan penyelewengan hukum. AS jelas tidak akan memberikan akses seluasluasnya pada Penuntut Umum ICC untuk melakukan penyelidikan atas warganya.

AS menghendaki agar dimulainya investigasi terhadap kejahatan yang berada dalam yurisdiksi ICC tidak terletak pada independent prosecutor tersebut, tetapi harus meminta ijin terlebih dahulu atau disetujui oleh DK-PBB. Usulan tersebut akan memberikan keuntungan dan peran yang sangat besar bagi AS, karena negara ini merupakan salah satu anggota DK-PBB yang bisa menggunakan hak vetonya. 
Karenanya sebelum tugas ICC dimulai secara resmi, AS telah berusaha sekuat tenaga untuk menghalangi tercapainya pembentukan ICC.

c. Tekanan AS terhadap PBB

Pembentukan ICC diwarnai pertentangan dari AS di mana sehari sebelum mahkamah itu resmi bekerja, yaitu pada tanggal 30 Juni 2002, AS memveto resolusi perpanjangan perdamaian PBB di Bosnia, sebagai protes pada penolakan DK PBB untuk mengecualikan pasukan penjaga perdamaian (Peace Keeping Force) dari jangkauan ICC. Pemerintah AS melakukan tekanan politik terhadap DK PBB, berusaha membuat para anggota dewan sepakat memberikan kekebalan hukum pada AS dari pasal 12 Statuta Roma yang berbunyi bahwa ICC memiliki yurisdiksi terhadap negara dimana kejahatan tersebut terjadi merupakan State Party, atau negara dari pelaku kejahatan merupakan State Party. Mengingat pasal tersebut, maka bisa saja terjadi Peace Keeping Force yang berasal dari negara yang bukan State Party dari Statuta Roma, tetapi karena mereka bertugas di wilayah teritorial negara yang menjadi Negara Pihak, dan di negara tersebut terjadi salah satu kejahatan yang menjadi yurisdiksi ICC, maka pasukan perdamaian tersebut beresiko untuk dituntut di ICC, padahal misi yang diemban oleh pasukan penjaga perdamaian yang sebagian besar berasal dari AS adalah untuk menjaga kepentingan AS dan global.

Untuk itulah pemerintahan Bush mengancam jika DK PBB menolak memberi keistimewaan itu, maka pasukan AS akan ditarik dari Bosnia. Diancam seperti itu, para anggota DK PBB masih tunduk kepada AS, karena jika AS sampai keluar dari pasukan perdamaian $\mathrm{PBB}$, kekuatan pasukan tersebut akan sangat melemah. Bagaimanapun juga, tentara AS memberikan sumbangan personil dan dana yang sangat signifikan terhadap kinerja pasukan perdamaian PBB. Dan akhirnya AS berhasil mengambil keuntungan dari situasi Bosnia tersebut. DK PBB pun terpaksa memberikan persetujuannya atas hak kekebalan hukum (hak kapitulasi) tentara AS selama satu tahun. Pada bulan Juli 2003, resolusi tersebut diperpanjang masih dalam alasan yang sama. Namun pada Juli 2004 DK PBB tidak lagi bisa menanggung tekanan AS tersebut. Bagi PBB perpanjangan resolusi tersebut adalah sebuah pelecehan yang tidak bisa lagi ditanggung.

d. Adanya Undang-Undang Invasi oleh AS

Pada bulan Juni 2003 AS kembali memperoleh keistimewaan dari DK PBB. Dengan demikian AS dengan mengabaikan kehendak masyarakat dunia, berhasil memberlakukan kekebalan hukum di seluruh dunia terhadap tentara dan pejabatnya. Dengan begitu mereka tidak akan dituntut. Selain itu pemerintah AS mengeluarkan 
undang-undang yang disebut Hague Invasion Act (Undang-Undang Invasi), yaitu Undang-Undang Penyerbuan Den Haag, untuk membebaskan warga AS yang ditahan di Den Haag dengan kekerasan. Dengan alasan inilah, militer AS selalu berada dalam posisi sebagai pelaku kejahatan perang dan pelanggaran HAM.

\section{Dominasi Amerika Serikat: Sebuah Hambatan Good World Governance}

Dari kasus-kasus yang terurai sebelumnya jelas terlihat bahwa AS lebih mengutamakan sikap unilateralisnya. AS yang sering membanggakan dirinya sebagai sebuah negara dengan tradisi demokrasi paling kuat di dunia dan senantiasa mendengungkan tekadnya menegakkan demokrasi dan HAM justru menentang eksistensi Perserikatan Bangsa Bangsa khususnya ICC.

Sebagaimana terurai sebelumnya bahwa paling tidak ada 8 hal yang harus dipenuhi untuk mencapai sebuah good governance dalam hal ini good world governance yaitu participatori, konsensus, akuntabel, transparan, responsif, efektif and efisien, adil dan inklusif serta mematuhi peraturan hukum yang berlaku. Untuk memahami good world governance maka tentu kita akan mulai dari eksistensi PBB sebagai manifestasi pemerintahan dunia yang mana di dalam markas berkasnya nya Negara-negara di dunia ini menempatkan perwakilannya. Di lembaga internasional PBB inilah pada dasarnya setiap negara bangsa berharap besar bahwa sebuah good world governance akan terwujud, namun kenyataan memang memperlihatkan bahwa PBB belum bisa berperan secara maksimal. Ada beberapa hambatan dalam proses pencapaian good world governance (dalam hal ini oleh PBB), namun hambatan yang utama adalah sulitnya supremasi hukum internasional ditegakkan, hal ini tampak sekali pada kebijakan sistem penyelesaian kasus Irak yang dilakukan oleh Amerika sebagai sebuah negara bukan PBB yang nota bene adalah organisasi internasional, sehingga jelas lemahnya posisi tawar PBB terhadap AS. Keadilan dan tegaknya hukum internasional yang menjadi salah satu rangkaian syarat tercapainya good world governance sulit terwujud di tengah-tengah hegemoni Amerika Serikat di Dunia.

Melihat kasus Irak khususnya proses peradilan Saddam, sangat tampak bahwa PBB masih sangat inferior jika dihadapkan dengan kepentingan sepihak Amerika Serikat. Meskipun sebagian besar negara anggota PBB tidak sepakat penyerangan terhadap Irak dan lebih khusus proses hukuman terhadap Saddam di Iraqi Special Tribunal namun PBB tidak bisa berbuat apa-apa. Kebijakan luar negeri AS pasca tragedi WTC yaitu pre-emptive action dan unilateralis kepada negara-negara yang "dianggap" teroris ternyata menimbulkan tragedi lain yang tidak kalah besar yaitu 
belum tercapainya good world governance. Hal ini tentu menjadi masalah tersendiri tidak hanya bagi PBB secara institusional tetapi juga bagi negara-negara bangsa di dunia untuk mencari solusi agar dapat mencapai bargaining position dengan AS sehingga tatanan masyarakat dunia yang adil dan saling menghargai dapat terwujud.

\section{E. Penutup}

Dari paparan di atas dapat disimpulkan beberapa hal sebagai berikut: pertama, proses peradilan Saddam Hussein yang dinilai menyalahi aturan hukum internasional adalah suatu bukti nyata bahwa aksi unilateral Amerika Serikat menyerang negara bangsa lain dengan dalih war on terrorism dalam hal ini Irak dan hegemoninya di Dunia ini merupakan sebuah tragedi yang menjadi faktor penghambat terwujudnya good world governance. Kedua, proses pencapaian tatanan masyarakat dunia yang berkeadilan sosial dan tidak lagi mengedepankan perang atau penyelesaian fisik sebagai solusi dari suatu permasalahan akan tercapai jika Perserikatan Bangsa-Bangsa sebagai manifestasi negara-negara di dunia ini dapat mandiri dan mempunyai bargaining position yang kuat terhadap dominasi Amerika Serikat.

\section{DAFTAR PUSTAKA}

Anom, Andari Karina. 2006. "Dari Nuremberg sampai Bagdad". Majalah Tempo Edisi 13-19 November.

Atmasasmita, Romli. 1998. Kapita Selekta: Hukum Pidana Internasional. Bandung: Putra A Bardin.

Bremer, L. Paul dikutip http://www.cpairaq.org/ regulations/20030516_CPAREG_1_ The_Coalition_Provisional_Authority_pdf.

Bush, Goerge W., "Freedom at war with Fear", dikutip dari: http:/ / www.whitehouse.gov/ news/releases/2001/09/20010920-8.html

Cipto, Bambang. 2003. Politik dan Pemerintahan Amerika. Yogyakarta: Lingkaran.

Coalition Provisional Authority Order Number 48: Delegation of Authority Regarding an Iraqi Tribunal',CPA/ORD/9 Dec 2003/48 (2003) (IST Statute), IST

Department of State, Quarterly Update to Congress: Section 2207 Report on Iraq Relief and Reconstruction (Januari 2004). 
Djunaedi, Eddy. 1998. “Mengapa AS Tidak Setuju dengan Statuta ICC?”, Varia Peradilan, Majalah Hukum Tahun XVI No. 184.

G. John Ikenberry. 2004. "Illusions of Empire: Defining the New American Order", dalam Foreign Affairs, Vol. 83, No. 2, March/April 2004.

Garis Besar Pemerintahan Amerika Serikat. 2000. Office of International Information Programs, United States Department of State.

Geneva Convention Relative to the Treatment of Prisoners of War of August 12 1949", The Geneva Conventions of August 12 1949, ICRC, Geneva.

http://www.globalpolicy.org/intljustice/tribunals/iraq/2005/1019fairness.htm diakses 14 Juli 2007, pukul 16:11 WIB.

http://www.ranesi.nl /arsipaktua/timurtengah/irak/tribunal_irak.html diakses 12 Juli 2007, pukul 20:35 WIB.

http://www.suaramerdeka.com/ harian/0406/21/opi2.htm.

Katzenstein, Peter J., 2005. "Conclusion: National Security in a Changing World", dalam Peter J. Katzenstein (ed.), The Culture of National Security: Norm and Identity in World Politics, dalam Suzie Sudarman, "Norma-norma, Identitas, dan Politik Luar Negeri AS Periode ke-2 Bush”. Jurnal Studi Amerika, Vol. X No. 2, Juli-Desember, Pusat Kajian Wilayah Amerika Universitas Indonesia, Jakarta

Kehoe, Greg. 2005. "A Slow Search for Justice in Iraq". Legal Times, 24 January; Department of State, Quarterly Update to Congress: Section 2207 Report on Iraq Relief and Reconstruction

Kompas, Kamis, 18 Desember 2003. “Arah Pengadilan Saddam: Sentuhan AS, tetapi Dikemas atas Nama Irak”, dalam http:/ /www.kompas.com/kompascetak/ 0312/18/sorotan/753159.htm

Konvensi Genewa III mengenai Perlakuan terhadap Tawanan Perang, Convention relative to the Treatment of Prisoners of War of August 121949 “, The Geneva Conventions of August 12 1949, Geneva: International Committee of the Red Cross

Konvensi IV Den Haag. 1907. Mengenai Hukum dan Kebiassan Perang di Darat yang judul lengkapnya adalah Convention Respecting to the Laws and Customs of War on Land merupakan penyempurnaan dari Konvensi II 
Den Haag (1899) mengenai Hukum dan Kebiasaan Perang di Darat, dalam Arlina Permanasari et.al. (1999), Pengantar Hukum Humaniter, International Committee of the Red Cross, Jakarta

Kuncahyono, Trias. 2005. Bulan Sabit di Atas Baghdad. Jakarta: Penerbit Buku Kompas Lake, David A., and Patrick M. Morgan. 1992. Regional Order Building Security in a New World. United States of America: Pensylvania State University Press

Millah, Vol V, No. 2, 2005.Yogyakarta: Magister Studi Islam UII

President of the United States. 2002. The National Security Strategy of the United States of America

The Former Iraqi Government on Trial, A Human Right Watch Briefing Paper, http://hrw.org/backgrounder/mena/iraq1005/iraq1005.pdf

The World Book Multimedia Encyclopedia (C) 2005 World Book, Inc. 233 North Michigan Avenue Suite 2000 Chicago, Illinois 60601

Widjajanto, Andi. 2007. "Komplikasi Hukum Tertangkapnya Saddam Hussein", dikutip melalui http://www.kompas.com/ kompas-cetak/0312/17/Jendela /744944.htm. 